\title{
Minimization of $\mathrm{SO}_{2}$ Emissions at ADGAS (Das Island, UAE): I- Current vs. Modified Schemes
}

Samir I Abu-Eishah ${ }^{1 *}$, Haitham SA Babahar ${ }^{2}$ and Munjed Maraqa ${ }^{3}$

${ }^{1}$ Chemical and Petroleum Engineering, UAE University, AI Ain, UAE

${ }^{2}$ Process Engineer, ADGAS Co., AI Ain, UAE

${ }^{3}$ Civil and Environmental Engineering, UAE University, Al Ain, UAE

\begin{abstract}
The objective of this work is to explore feasible technologies to minimize $\mathrm{SO}_{2}$ emissions from ADGAS and investigate the impact of implementing such modifications on the ambient air quality at the Island. In order to achieve this, two $\mathrm{SO}_{2}$ emission minimization schemes have been proposed; a Fuel Gas Sweetening (FGS) scheme and a Flue Gas Desulfurization (FGD) scheme.The FGS scheme involves (1) directing most of the $\mathrm{H}_{2} \mathrm{~S}$ in the fuel gas to the Sulfur Recovery Units (SRUs) where it is converted to elemental sulfur. The unconverted $\mathrm{H}_{2} \mathrm{~S}$ will be routed to the SRUs' incinerators where it is oxidized to $\mathrm{SO}_{2}$, and (2) revamping the UGAs internals (by replacing current packing with an approved higher efficiency packing) in order to produce a sweeter fuel gas. The FGD scheme involves installation of SW-FGD units downstream the SRUs' incinerators where the $\mathrm{SO}_{2}$ in the flue gas is scrubbed by the plant spent seawater in a dedicated packed bed absorber and converting it to harmless sulfate ions (natural constituents of the seawater) that will be safely disposed to the sea.

The FGS scheme is expected to reduce the $\mathrm{H}_{2} \mathrm{~S}$ content in the fuel gas by $94 \%$ and result in decreasing the total $\mathrm{SO}_{2}$ emissions due to fuel gas usage by $98 \%$. The FGD scheme is expected to reduce the $\mathrm{SO}_{2}$ emissions due to incomplete sulfur recovery in the SRUs by $99.5 \%$. Implementation of both schemes is expected to reduce the total $\mathrm{SO}_{2}$ emissions by $77 \%$. Most of the remaining $\mathrm{SO}_{2}$ emissions $(23 \%)$ are due to the continuous flaring of the flash gas in the plant. In Part II of this work, the BREEZE AERMOD Pro Software is used to predict the $\mathrm{SO}_{2}$ Ground Level Concentration (GLC) for the current and modified $\mathrm{SO}_{2}$ minimization schemes. Compliance with the country limits and challenge with future regulatory standards have been examined.
\end{abstract}

Keywords: Minimization of $\mathrm{SO}_{2}$ emissions; Fuel gas sweetening; Flue gas desulfurization; Seawater scrubbing

\section{Nomenclature}

\section{Acronyms}

\begin{tabular}{|c|c|}
\hline ADGAS & Abu Dhabi Gas Liquefaction Company \\
\hline ADMA-OPCO & Abu Dhabi Marine Operating Company \\
\hline BFW & Boiler Feed Water \\
\hline CEPCl & Chemical Engineering Plant Cost Index \\
\hline DEA & Diethanol Amine \\
\hline EAD & Environmental Agency - Abu Dhabi \\
\hline FEA & Federal Environmental Agency \\
\hline FGD & Flue Gas Desulfurization \\
\hline GLC & Ground Level Concentration \\
\hline HETP & Height of Equivalent Theoretical Plate \\
\hline MW & Molecular weight \\
\hline PGA & Process Gas Absorber \\
\hline ppm & parts per million \\
\hline SW & Seawater \\
\hline SRU & Sulfur Recovery Unit \\
\hline UAE & United Arab Emirates \\
\hline UGA & Utility Gas Absorber \\
\hline US EPA & Wnited States Environmental Protection Agency \\
\hline WHB & Waste Heat Boiler \\
\hline WHO & World Health Organization \\
\hline
\end{tabular}

\section{Symbols}

\begin{tabular}{|c|c|}
\hline$a$ & Interfacial contact area \\
\hline$D$ & diameter of packed bed column \\
\hline$F$ & Packing factor \\
\hline $\mathrm{H}_{\mathrm{OG}}$ & Overall height of a gas transfer unit \\
\hline
\end{tabular}

\begin{tabular}{|c|c|}
\hline $\mathrm{K}_{\mathrm{OG} . a}$ & Overall mass transfer coefficient based on gas phase \\
\hline $\mathrm{N}_{\mathrm{OG}}$ & Number of overall mass transfer units \\
\hline$P$ & Pressure \\
\hline$S$ & Solubility of $\mathrm{SO}_{2}$ \\
\hline$T$ & Temperature \\
\hline$X$ & Seawater initial salinity \\
\hline$X$ & Ion concentration in seawater \\
\hline$y_{\text {in }}$ & Mole fraction of pollutant at absorber inlet \\
\hline$y_{\text {out }}$ & Mole fraction of pollutant at absorber outlet \\
\hline$Z$ & Packed bed total height \\
\hline
\end{tabular}

\section{Introduction}

Das Island is a well offshore island of the UAE in the Arabian (Persian) Gulf, $160 \mathrm{~km}$ of mainland and inhabited by the personnel of oil and gas industries. The main function of the Abu Dhabi Gas Liquefaction Co. (ADGAS) plant at Das Island is to process sour natural gas supplied to produce Liquefied Natural Gas (LNG), Liquefied Petroleum Gas (LPG), paraffinic naphtha and sulfur. Some of the natural gas fed to ADGAS comes directly from gas fields as non-associated gas. The processing of

*Corresponding author: Samir I Abu-Eishah, Chemical and Petroleum Engineering, UAE University, Al Ain, UAE, Tel:971-3-713-5100; E-mail: s.abueishah@uaeu.ac.ae

Received March 22, 2014; Accepted April 17, 2014; Published April 25, 2014

Citation: Abu-Eishah SI, Babahar HSA, Maraqa M (2014) Minimization of $\mathrm{SO}_{2}$ Emissions at ADGAS (Das Island, UAE): I- Current vs. Modified Schemes. J Pet Environ Biotechnol 5: 173. doi:10.4172/2157-7463.1000173

Copyright: (C) 2014 Abu-Eishah SI, et al. This is an open-access article distributed under the terms of the Creative Commons Attribution License, which permits unrestricted use, distribution, and reproduction in any medium, provided the original author and source are credited. 
sour gases from the LNG trains at ADGAS involves $\mathrm{SO}_{2}$ emissions that mainly result from fuel gas usage to produce steam and electricity and incomplete recovery of sulfur from acid gases. The $\mathrm{SO}_{2}$ emissions affect the ambient air quality in the Island and this has the potential to affect the health of its residents. Throughout its history, ADGAS suffers high rates of $\mathrm{SO}_{2}$ emissions.

\section{Impact of $\mathrm{SO}_{2}$ Emissions}

$\mathrm{SO}_{2}$ is a non-combustible gas that is heavier than air and its emission is associated with a wide range of health (e.g., respiratory illness) and environmental (e.g., acid rain) impacts due to the way it reacts with other substances in the air [1-3]. $\mathrm{SO}_{2}$ emissions are greatly controlled by international and national regulations that establish limits of discharging $\mathrm{SO}_{2}$ to the atmosphere. The main objective of such regulations is to enhance ambient air quality and prevent the environmental effects of the $\mathrm{SO}_{2}$ emissions.

$\mathrm{SO}_{2}$ emissions have global, regional and local impacts. Globally, the $\mathrm{SO}_{2}$ emitted has the potential to travel in any direction for hundreds of kilometers depending on climate conditions. $\mathrm{SO} 2$ is relatively stable in the atmosphere and has the ability to travel as far as $1000 \mathrm{~km} \mathrm{[1].}$ Regionally, $\mathrm{SO}_{2}$ emissions from ADGAS contribute to the high pollution levels in the western region of the Emirate of Abu Dhabi (UAE). The oil and gas industries are the main source of air pollution there and $\mathrm{SO}_{2}$ air pollution is dominating in that Region [4]. Locally, $\mathrm{SO}_{2}$ emissions from ADGAS affect the ambient air quality in Das Island. The high $\mathrm{SO}_{2}$ emissions there usually lead to air quality deterioration which might have health effects on the residents of the island (including ADGAS employees).

The magnitude of the impact of $\mathrm{SO}_{2}$ emissions necessitates the need to research all possible means to combat such impacts. This investigation should have a significant impact on the $\mathrm{SO}_{2}$ emissions from the ADGAS Plant in Das Island. The ultimate goal is to minimize the impact of the $\mathrm{SO}_{2}$ emissions at all levels and establish better environmental and occupational health for the residents of the Das Island.

\section{Constraints on the Minimization of $\mathrm{SO}_{2}$ Emissions at ADGAS}

Several constraints have been considered in the process of identifying the most suitable technologies to minimize the $\mathrm{SO}_{2}$ emissions from the ADGAS plant. These include:

- ADGAS plant is located in a remote area, nearly $180 \mathrm{~km}$ from the city of Abu Dhabi. Thus, any minimization technology must not depend on continuous resources supply from outside the Das Island.

- Any $\mathrm{SO}_{2}$ minimization scheme must take into consideration the limited area of the ADGAS plant which is crowded with processing units and equipment; therefore, it is preferable that any proposed plant modification exposes the minimum footprint in the Island.

\section{Sources of $\mathrm{SO}_{2}$ emissions within the ADGAS plant}

$\mathrm{H}_{2} \mathrm{~S}$ and $\mathrm{CO}_{2}$ are the main contaminants in the natural gas feed to ADGAS Liquefied Natural Gas(LNG) trains. The natural gas feed as received contains (2.5-5.5) $\mathrm{mol} \% \mathrm{H}_{2} \mathrm{~S}$ and (4.5-6.5) $\mathrm{mol} \% \mathrm{CO}_{2} . \mathrm{H}_{2} \mathrm{~S}$ is a very toxic and corrosive gas that freezes at very low temperatures. $\mathrm{CO}_{2}$ is an impurity that also freezes at low temperatures and would, therefore, block the cryogenic sections of the plant where the natural gas feed is cooled to $-160^{\circ} \mathrm{C}$. Therefore, both gases must be removed in order to meet the cryogenic liquefaction requirements and the endproducts' specifications.

ADGAS operates three LNG processing trains. Trains 1 and 2 are identical, both process associated and non-associated gas and each is designed to produce 180 ton/h LNG. Train 3 processes non-associated gas direct from the gas field and is designed to produce 384 ton/h LNG.

The processing of the sour gases at ADGAS involves Hi-Pure Benfield ${ }^{\circ}$ units (certified by UOB) that utilize a two-stage sweetening process: The gas feed is treated in the first absorber with hot potassium carbonate solution which reduces the $\mathrm{CO}_{2}$ and $\mathrm{H}_{2} \mathrm{~S}$ contents to 2,000 ppm and $800 \mathrm{ppm}$, respectively. In the second absorber it is treated with Diethanol Amine Solution (DEA) which reduces $\mathrm{H}_{2} \mathrm{~S}$ to $<4 \mathrm{ppm}$ and $\mathrm{CO}_{2}$ to $<50 \mathrm{ppm}$. The removed acid gases $\left(\mathrm{H}_{2} \mathrm{~S}\right.$ and $\left.\mathrm{CO}_{2}\right)$ are then sent to Sulfur Recovery Units (SRUs) where molten sulfur is recovered from the $\mathrm{H}_{2} \mathrm{~S}$ by the Super Claus Process.

The main process sources of $\mathrm{SO}_{2}$ emissions at ADGAS can be classified as flare and non-flare sources. Currently, these respectively constitute 1706 ton/yr (10.6\%) from flare sources and 14,385 ton/yr (89.4\%) from non-flare sources. The flare- $\mathrm{SO}_{2}$ emission sources mainly include $\mathrm{SO}_{2}$ emissions from pilot and purge usage and from flaring of sour gases in the case of emergency. The $\mathrm{SO}_{2}$ emission sources from flares are considered intermittent except for the continuous flaring of flash gases from the sweetening plants. The non-flare $\mathrm{SO}_{2}$ emission sources include $\mathrm{SO}_{2}$ emissions from the fuel gas usage (e.g., in boilers, fired heaters, and incinerators) and from the incomplete sulfur recovery units.

The fuel gas usage within the ADGAS plant contributes to about $20 \%$ of the plant total $\mathrm{SO}_{2}$ emissions due to its $\mathrm{H} 2 \mathrm{~S}$ containment. This is a concern only for Trains 1 and 2 which utilize fuel gas with $1200 \mathrm{ppm}$ $\mathrm{H}_{2} \mathrm{~S}$ produced in the UGAs of Trains 1 and 2. It is also a concern for the ADMA-Gas Turbines (ADMA-GTs) which utilize untreated fuel gas with an $\mathrm{H}_{2} \mathrm{~S}$ content of $2.2 \mathrm{~mol} \%$. i.e., the fuel gas usage in the ADMAGTs is one of the major sources of the $\mathrm{SO}_{2}$ emissions within the ADGAS plant. There is no concern for Train 3 UGA since it utilizes very sweet gas with $\mathrm{H} 2 \mathrm{~S}<5 \mathrm{ppm}$.

The tail gas off the SRUs is incinerated and the resultant flue gas is vented to the atmosphere through the incinerators stacks. The contribution of the vented flue gas accounts for about $70 \%$ of total $\mathrm{SO}_{2}$ emissions from the ADGAS plant. Thus, the SRUs are considered the major contributors to $\mathrm{SO}_{2}$ emissions within the company. The various $\mathrm{SO}_{2}$ emission sources within the ADGAS plant are presented in Figure 1.

\section{Previous investigations on $\mathrm{SO}_{2}$ emission minimization at ADGAS}

Atkins [5] investigated aerial emissions on Das Island to determine compliance of aerial emission sources with environmental regulations and assessed the impact of these emissions on ambient air quality and concluded that anyone spending long periods on Das Island could experience elevated health risks from exposure to $\mathrm{SO}_{2}$. Atkins used US EPA ISCST3 for modeling the air dispersion. Atkins [5] recommended enhancing the SRUs from Claus to

Super Claus technology and reducing the sulfur content of the fuel gas. Al-Nuaimi [6] followed the Atkins recommendation to upgrade the SRUs from Claus to Super Claus process which will reduce the $\mathrm{SO}_{2}$ ground-level concentration in Das Island by about 30\%. In his work, Al Nuaimiused BREEZE ISC3 for air dispersion modeling. 


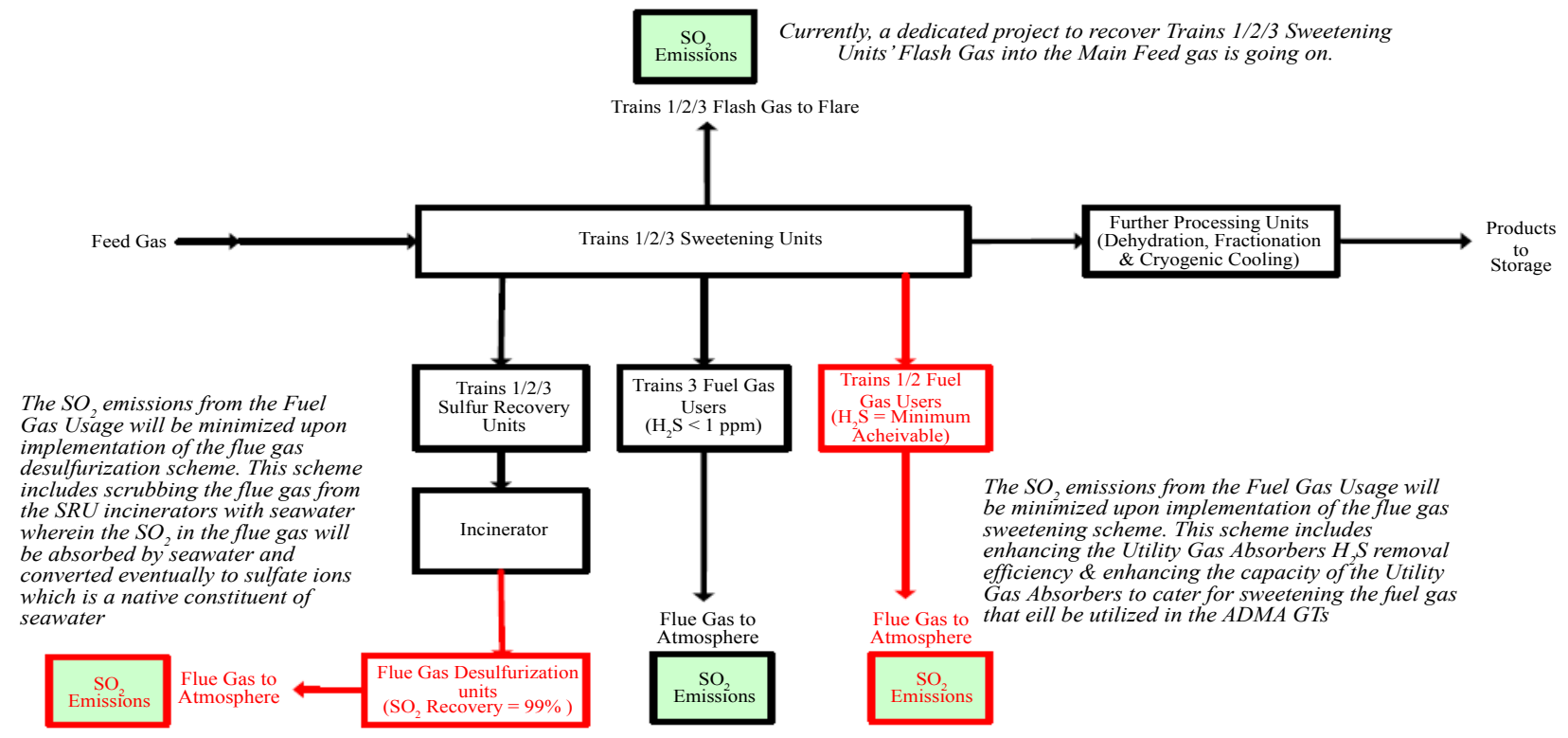

Figure 1: $\mathrm{SO}_{2}$ emission sources within the ADGAS plant at Das Island (UAE).

\begin{tabular}{|c|c|c|c|}
\hline Packing Type & Void Fraction, $\varepsilon$ & $\operatorname{HETP*}^{*}(\mathrm{~m})$ & $\Delta \mathrm{P}\left(\mathrm{mm} \mathrm{H} \mathrm{H}_{2} \mathrm{O} / \mathrm{m}\right.$ packing $)$ ** \\
\hline 1" HYPAK ${ }^{\circledast}$ & 0.96 & 0.40 & 11.67 \\
\hline IMTP ${ }^{\circledR} \# 40$ & 0.98 & 0.40 & 5.83 \\
\hline
\end{tabular}

*HETP is for a standard test of iso-octane/toluene at $98.4 \mathrm{kPa}$ in a packed tower (15.2 in diameter and $10 \mathrm{ft}$ height), capacity factor $=0.20 \mathrm{ft} / \mathrm{s}$.

${ }^{\star \star} \Delta \mathrm{P}$ is for a standard test of Air/Water system (inlet gas rate $=1.10 \mathrm{~kg} /\left(\mathrm{m}^{2} . \mathrm{s}\right)$, liquid rate $=6.8 \mathrm{~kg} /\left(\mathrm{m}^{2} . \mathrm{s}\right)$ in packed bed $(30$ in diameter and $10 \mathrm{ft}$ height).

Table 1: Random packing characteristics: IMTP ${ }^{\circledR} 40$ [7] vs. 1" HYPAK ${ }^{\circledR}$ [8]. Further details about IMTP $\# 40$ can be found elsewhere [7].

In the 2001/2002 revamp of Trains 1 and 2 Acid Gas Removal Units, ADGAS replaced the old HYPAK ${ }^{\circledR}$ random packing of the HiPure Benfield units with Koch-Glitsch IMTP” \#40 random packing. The IMTP' packing was selected based on its improved hydraulics, mass transfer performance and its lower pressure drop [7] (Table 1). The performance of the Process Gas Absorber (PGA), which processes the main gas feed to Trains 1 and 2 , has been enhanced in exactly the same manner as the UGAs. That is, the outlet H2S was reduced from 1500 ppm to $450 \mathrm{ppm}$ ( $70 \%$ reduction of the design value). Based on these results, it is proposed here to replace the current 1 " HYPAK ${ }^{\circledR}$ random packing of the UGAs of Trains 1 and 2 with IMTP $^{\circledR} \# 40$ random packing [8]. In2005, ADGAS commissioned Shell Global Solutions (SGS) to carry out a study with the objective of identifying measures to reduce emissions from the ADGAS LNG plant at Das Island. SGS pointed out that the poor ADGAS $\mathrm{SO}_{2}$ emission performance is due to the unreliability of the SRUs. Since flared gases might contain as high as $15 \mathrm{~mol} \% \mathrm{H}_{2} \mathrm{~S}$ and in order to reduce the $\mathrm{SO}_{2}$ emissions, SGS proposed the recovery of the flash gases from the sweetening plant and use them as fuel gas in the SRUs' incinerators [9]. In 2006, a process optimization atADGAS has led to improving the sulfur recovery efficiency to $>99 \%$ by adding a Super Claus process in all the three LNG trains.

In 2007, ADGAS set itself an aggressive plan for accelerated implementation of flaring and emission reductions. ADGAS planning to reduce total gas flaring from 15 MMSCFD in 2007 to 1 MMSCFD by 2010 through four schemes: major flaring reductions, energy efficiency improvement, SRU reliability and integrity improvement, and other flaring reductions.

\section{Proposed minimization schemes for the $\mathrm{SO}_{2}$ emissions at ADGAS}

The selection of optimum gas sweetening method is a hard task and depends on various factors [10] such as type and concentration of contaminants in the gas, desired degree of contaminant removal, required selectivity of the acid gas removal, temperature, pressure, volume and composition of the gas to be processed, $\mathrm{CO}_{2} / \mathrm{H}_{2} \mathrm{~S}$ ratio in the gas, and the desirability of sulfur recovery due to process or environmental issues [11].

In order to minimize the resultant $\mathrm{SO}_{2}$ emissions from fuel gas usage, it is also proposed here to improve the sweetening efficiencies of Trains 1 and 2 UGAs and sweeten the fuel gas supplied to the ADMAGTs. This can be done through rejuvenation of the UGAs (i.e., the main fuel gas producers) through revamping the UGAs internals, and at the same time utilizing these absorbers to cater for the ADMA-GTs' fuel gas demand. This can be done by replacing the UGAs' current packing with a higher efficiency packing. This is expected to result in the enhancement of the mass transfer efficiency between the fuel gas and the absorbing agent in the UGAs. It is also proposed here to install Seawater-Flue Gas Desulfurization (SW-FGD) units downstream the SRUs' incinerators. In these units, the $\mathrm{SO}_{2}$ in the flue gas will be scrubbed by the plant spent seawater in a dedicated packed bed absorber. In this case, the $\mathrm{SO}_{2}$ in the flue gas will be converted to sulfate ions which are natural constituents of the seawater. The FGD system in this case must have the capability of recovering not less than $99.5 \%$ of the $\mathrm{SO}_{2}$ emitted from the SRU incinerators. The recovered $\mathrm{SO}_{2}$ must be disposed in the most environmentally-friendly manner. A schematic diagram of current and proposed $\mathrm{SO}_{2}$ emission minimization schemes are shown in Figure 2. 


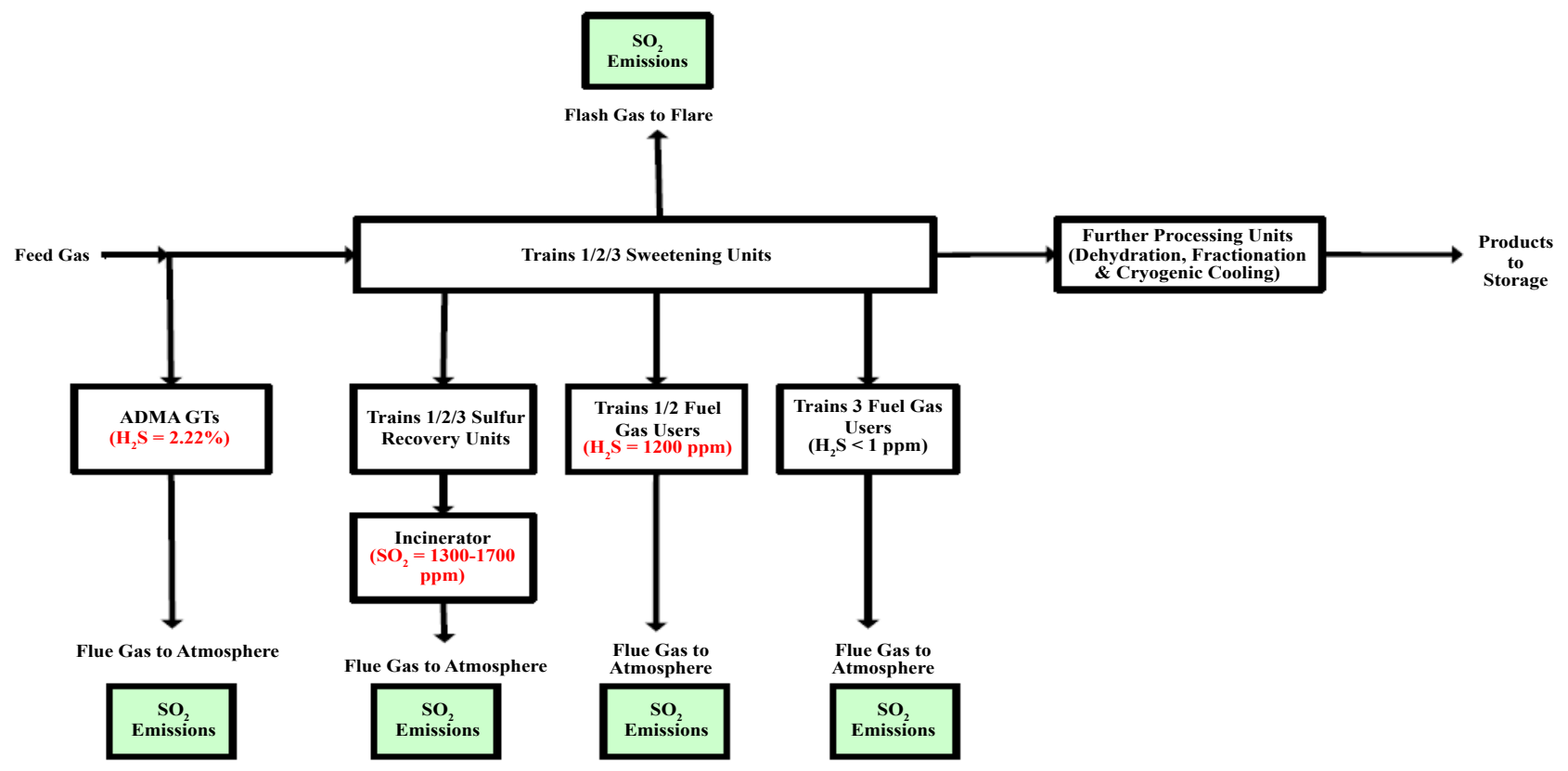

Figure 2: Scope of $\mathrm{SO}_{2}$ minimization schemes at ADGAS.

\begin{tabular}{|c|c|c|c|c|}
\hline Characteristic & $\begin{array}{l}\text { Acid gas feed } \\
\text { to UGAs }\end{array}$ & $\begin{array}{c}\text { Sweet gas from } \\
\text { UGAs }\end{array}$ & $\begin{array}{c}\text { Lean carbonate } \\
\text { solution }\end{array}$ & $\begin{array}{l}\text { Rich carbonate } \\
\text { solution }\end{array}$ \\
\hline $\mathrm{H}_{2} \mathrm{~S}(\mathrm{~mol} \%)$ & 2.22 & 0.0072 & - & 0.42 \\
\hline $\mathrm{CO}_{2}(\mathrm{~mol} \mathrm{\%})$ & 3.67 & 0.0094 & - & 0.70 \\
\hline $\mathrm{K}_{2} \mathrm{CO}_{3}$ & - & - & 5.41 & 5.35 \\
\hline Molar flow rate $(\mathrm{kmol} / \mathrm{h})$ & $2,442.8$ & $2,299.3$ & $9,430.66$ & $9,574.22$ \\
\hline Mass flow rate (ton/h) & 49.03 & 43.14 & 234.95 & 240.70 \\
\hline Pressure (barg) & 15.45 & 15.5 & 24 & 15.9 \\
\hline T emp. $\left({ }^{\circ} \mathrm{C}\right)$ & 69 & 85 & 121 & 93 \\
\hline
\end{tabular}

Table 2: Material Balance on the Acid Gas Feed Sweetening in the UGAs of Trains $1 \& 2$.

After choosing the minimization schemes, the following has been made

- Study the impact of the proposed $\mathrm{SO}_{2}$ emission minimization schemes on the ADGAS plant operations. Such study will be exclusive of the associated utility requirements, real plant tie-ins, associated control system, and off-site (e.g., flares) connections

- Design of all process equipment for the proposed schemes to fit real plant conditions (e.g., feed composition, flow, temperature, pressure, etc.) for both fuel gas sweetening and flue gas desulfurization schemes.

- Conduct a cost-analysis study to estimate the cost associated with the selection of the minimization schemes of $\mathrm{SO}_{2}$ emissions.

- Predict the impact of the proposed $\mathrm{SO}_{2}$ emission minimization schemes on the Das Island air quality. The results of this part will be presented in Part II of this work.

Impact of the proposed $\mathrm{SO}_{2}$ emission minimization schemes on plant operations

The objective of proposed $\mathrm{SO}_{2}$ emission minimization schemes is to minimize ADGAS $\mathrm{SO}_{2}$ emissions due to fuel gas usage. The implementation of the proposed fuel gas sweetening scheme requires increasing the entry temperature of the fuel gas feed to the UGAs, replacing of the UGAs' packings from HYPAK to IMTP, utilizing UGAs to sweeten the ADMA-GTs' fuel gas, and modifying the treatment capacity of the UGAs (i.e., circulation rates of fuel gas feed and lean carbonate solution). On the other hand, implementing the SW-FGD scheme will be associated with the determination of seawater and boiler feed water $(\mathrm{BFW})$ requirements, estimation of the steam produced in the waste heat boilers and its utilization in the ADGAS plant, and determination of the neutralization and oxidation requirements of the spent seawater before being disposed to sea.

Heating fuel gas feed to trains 1 and 2 UGAs: One aspect of the fuel gas sweetening scheme is the way of establishing the same process conditions in Trains 1 and 2 UGAs (to be similar to those of Trains 1 and 2 PGAs) in order to promote the maximum $\mathrm{H}_{2} \mathrm{~S}$ removal efficiency. The fuel gas feed to the UGAs has to be heated to $69^{\circ} \mathrm{C}$ (= gas feed entry temperature to PGAs) using Low Pressure Steam (LS). The required steam can be supplied from the mean-steam distribution system of Trains 1 and 2, taking into account the steam generated in the waste heat boilers upon implementing the flue gas desulfurization scheme. Table 2 shows basic material balance on the acid gas feed sweetening process in the UGAs of Trains 1 and 2 using hot $\mathrm{K}_{2} \mathrm{CO}_{3}$ solution. 
a. Process Gas Absorber $\left(T=69^{\circ} \mathrm{C} ; P=53\right.$ barg $)$

\begin{tabular}{|c|c|c|c|c|c|c|}
\hline Parameter & Yin & Yout & NOG & $\boldsymbol{Z}$ & HOG & KOG.a \\
\hline Unit & Mole fraction & Mole fraction & Transfer units & $\mathrm{m}$ & $\mathrm{m}$ & $\mathrm{k}$ \\
\hline $\mathrm{H}_{2} \mathrm{~S}$ & 0.0316 & 0.000426 & 4.34 & 13.39 & 3.09 & 0.393 \\
\hline $\mathrm{CO}_{2}$ & 0.0418 & 0.000448 & 4.53 & 13.39 & 2.95 & 0.410 \\
\hline
\end{tabular}

b. Utility Gas Absorber $\left(\mathrm{T}=69^{\circ} \mathrm{C} ; \mathrm{P}=15.45\right.$ barg $)$

\begin{tabular}{|c|c|c|c|c|c|c|c|}
\hline Parameter & Yin & Yout & NOG & Z & HOG & KOG.a \\
\hline Unit & Mole fraction & Mole fraction & Transfer units & $\mathrm{m}$ & $\mathrm{m}$ & $\mathrm{kmol} / \mathrm{kmol}$-mol/h.m ${ }^{2}$. Pa \\
\hline $\mathrm{H}_{2} \mathrm{~S}$ & 0.0222 & $7.220 \mathrm{E}-05$ & 5.75 & 19.48 & 3.39 & 0.393 \\
\hline $\mathrm{CO}_{2}$ & 0.0367 & $9.350 \mathrm{E}-05$ & 6.01 & 19.48 & 3.24 & 0.410 \\
\hline
\end{tabular}

* $130.42 \%$ excess capacity based on PGA removal efficiency; ** $104.57 \%$ excess capacity based on PGA removal efficiency.

Table 3: Mass Transfer Parameters and Carrying Capacity of PGA and UGA of Trains 1 and 2.

Packing replacements: The determination of the $\mathrm{H}_{2} \mathrm{~S}$ and $\mathrm{CO}_{2}$ concentrations from the outlet of the UGAs of Trains 1 and 2 under the proposed conditions requires the determination of the overall mass transfer coefficient $\left(\mathrm{K}_{\mathrm{OG} . \mathrm{a}}\right)$ at similar conditions (i.e., the PGAs system of Trains 1 and 2). Table 3 shows the mass transfer parameters and carrying capacity of the PGA and the UGA of Trains 1 and 2.

The proposed fuel gas sweetening scheme requires replacing the current Trains 1 and 2 UGAs HYPAK $^{\circ}$ packing to the higher efficiency IMTP' packing, catering UGAs to supply the required fuel gas to ADMA-Gas Turbines, and heating the fuel gas feed to the UGAs to establish the same conditions of the PGAs of Trains 1 and 2.

IMTP' has less $\mathrm{H}_{\mathrm{OG}}$ than HYPAK. The fact that the IMTP' has higher mass transfer coefficient $\left(\mathrm{K}_{\mathrm{OG}}\right)$ leads to decrease the height of the mass transfer unit $\left(\mathrm{H}_{\mathrm{OG}}\right)$ and thus provide more transfer units $\left(\mathrm{N}_{\mathrm{OG}}\right)$ for the same packing height $(\mathrm{Z})$. The $\mathrm{IMTP}^{*} \# 40$ packing has less HOG than the HYPAK ${ }^{\circ}$ packing. That is, the utilization of IMTP' packing will enhance the H2S-removal efficiency of the carbonate solution as long as there is a room in the carbonate solution for $\mathrm{H}_{2} \mathrm{~S}$ absorption.

The packing replacement in this work has resulted in $48.87 \%$ reduction in $\mathrm{H}_{\mathrm{OG}}$ (from 6.63 to $3.39 \mathrm{~m}$ ) and consequently increased the number of available transfer units $\left(\mathrm{N}_{\mathrm{OG}}\right)$ by $95.58 \%$ (from 2.64 to 5.75); i.e., almost doubled the carbonate solution removal capacity. Ultimately, the $\mathrm{H}_{2} \mathrm{~S}$ in the semi-sweet fuel gas treated in the UGAs was reduced by $93.98 \%$ (from 1200 to $72 \mathrm{ppm}$ ). Also, the proposed fuel gas sweetening scheme has resulted in $94.75 \%$ reduction in the $\mathrm{H}_{2} \mathrm{~S}$ content in the fuel gas feed to the boilers, $94 \%$ reduction $\mathrm{H}_{2} \mathrm{~S}$ content in fuel gas to all fuel gas users of Trains $1 \& 2$, and $99.67 \%$ reduction in the $\mathrm{H}_{2} \mathrm{~S}$ content in the fuel gas to ADMA-GTs.

Catering for the ADMA-GTs fuel gas demand and fuel gas and carbonate solution circulation rates: In order to cater for the ADMA-GTs fuel gas demand requires increasing Trains 1 and 2 UGAs treatment capacity by $18 \%$ (from 2,071 to $2,443 \mathrm{k} \mathrm{mol} / \mathrm{h}$ ). This will be accompanied with an increase in the lean carbonate solution circulation rate by about $20 \%$ (from 154 to $185 \mathrm{~m}^{3} / \mathrm{h}$ ). The original Trains 1 and 2 design capacities for the fuel gas feed and carbonate solution circulation rates are $3,401 \mathrm{kmol} / \mathrm{h}$ and $303 \mathrm{~m}^{3} / \mathrm{h}$, respectively. Thus, the rates of both fuel gas feed and carbonate solution are still within the design envelope of the UGAs. The current fuel gas supply to the ADMA-GTs is about $598 \mathrm{kmol} / \mathrm{h}$. Therefore, upon utilization of the UGAs to supply the required fuel gas to the ADMA-GTs, the UGAs load will increase to about $2,669 \mathrm{kmol} / \mathrm{h}$, which is still within the UGAs design capacity.

\section{Calculations required for the proposed fuel gas sweetening scheme}

As of the current conditions, the high-pressure gas feed at 53 bargis let down through a pressure control valve to 15.6 barg prior to being split into 2 main streams; one is directed to the UGAs of Trains 1 and 2 and the other to ADMA-GTs. The first is sweetened in the UGAs and fed to fuel gas system while the other is directly utilized in the ADMAGTs as a fuel gas without any treatment.

The target of the modified fuel gas sweetening scheme is to achieve minimum $\mathrm{H}_{2} \mathrm{~S}$ concentration at the UGAs outlet. This requires routing all the partially depressurized gases to the UGAs of Trains 1 and 2 and maximizing the UGAs efficiency through utilization of the high performance IMTP ${ }^{\circ}$ packing; this specification is limited due to the fact that all of the mass transfer parameters of the UGAs (including the packed bed diameter and height) are fixed. The implementation of the modified fuel gas sweetening scheme includes the determination of $\mathrm{H}_{2} \mathrm{~S}$ and $\mathrm{CO}_{2}$ concentrations at the UGAs outlets as well as the required fuel gas treating capacities in these UGAs. The data required for the material balances around the UGAs and the PGAs include the gas feed and the carbonate solution properties. The gas feed data of PGAs and UGAs of Trains 1 and 2 were retrieved from real plant ADGAS Process History Data (PHD). The average data for the gas feed composition, flow, temperature and pressure for a test period ofthree months (Dec 2005-Feb 2006) were collected. The operation of the plant during this test period was steady as the plant did not experience any upsets or sudden process trips. The carbonate solution composition data were collected from ADGAS Laboratory Daily Logs representing the results of the routine sampling of the various solutions used in the trains' sweetening plants. The flow, pressure and temperature of the carbonate solution were taken from PHD for the same test period.

The characteristics of the fuel gas hot $\mathrm{K}_{2} \mathrm{CO}_{3}$ solution before and after the UGAs and PGAs of Trains 1 and 2 along with fuel gas supply and demand of Trains 1 and 2 under current conditions are available elsewhere.

The heat input for each fuel gas user (e.g., boilers, fired heaters, and incinerators) has been calculated. The heat input for each train is then used as a basis for the determination of the required fuel gas flow (that will deliver the same heat input to that train) once the fuel gas composition is changed post implementing the proposed scheme.

The $\mathrm{H}_{2} \mathrm{~S}$ content in the sour gas feed has been reduced from 2.22 to $0.12 \mathrm{~mol} \%$ in the UGAs and from 3.16 to $0.0426 \mathrm{~mol} \%$ in the PGAs of Trains $1 \& 2$ using the hot $\mathrm{K}_{2} \mathrm{CO}_{3}$ solution. The main results are shown in Table 4 . 


\begin{tabular}{|c|c|c|}
\hline Characteristic & UGAs & PGAs \\
\hline Sour gas feed rate, $\mathrm{kmol} / \mathrm{h}$ & 2,071 & 11,719 \\
\hline $\mathrm{H}_{2} \mathrm{~S}$ in sour gas feed $(\mathrm{mol} \%)$ & 2.22 & 3.16 \\
\hline$\left(\mathrm{K}_{2} \mathrm{CO}_{3} /\right.$ Sour gas feed $)$ ratio & 5.04 & 4.10 \\
\hline Total $\mathrm{H}_{2} \mathrm{~S}$ removed $(\mathrm{kmol} / \mathrm{h})$ & 43.48 & 365.33 \\
\hline
\end{tabular}

Table 4: Sour Gas Treatment Results.

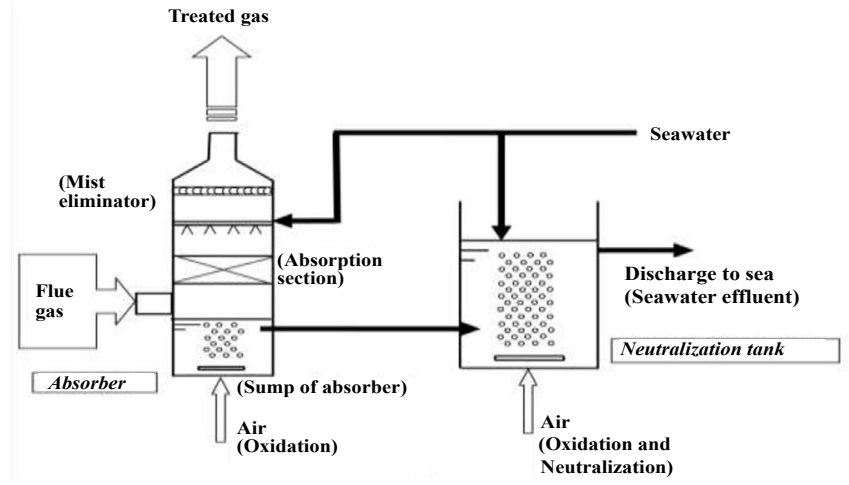

Figure 3: Simplified process flow diagram of a SW-FGD plant [25].

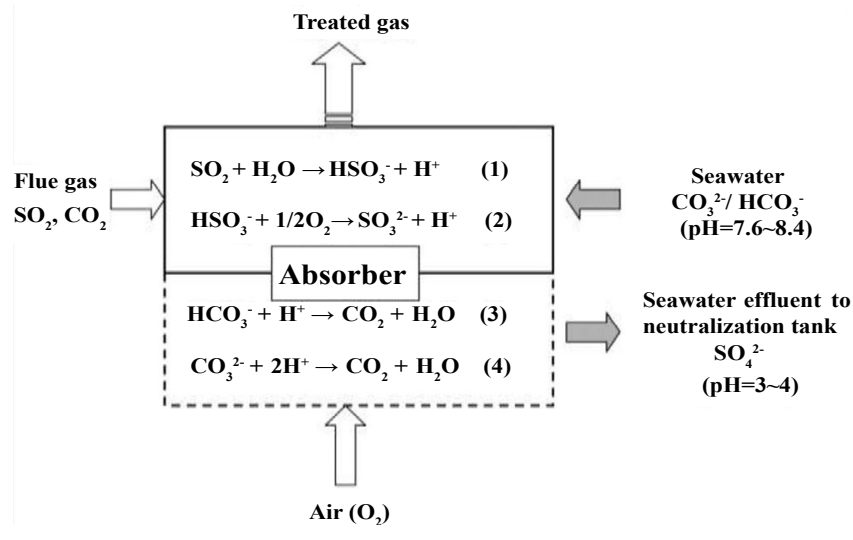

Figure 4: Reactions in the SW-FGD Process [25].

\section{The Seawater-Flue Gas Desulfurization Scheme}

The SW-FGD process is developing rapidly in fired power plants. It is a viable desulfurization option that can also be adopted in seashorelocated process plants [12]. It utilizes the natural alkalinity of the process plant spent seawater to absorb the $\mathrm{SO}_{2}$ from the flue gases. Seawater has a high capacity to absorb $\mathrm{SO}_{2}$ due to its carbonate and bicarbonate ions $[13,14]$. It is a convenient absorption medium for flue gases emitted from many industrial sites compared to all other alternatives proposed in the literature [15]. The SW-FGD process is considered as a promising technology environmentally sound from an engineering point of view [16]. The seawater scrubbing is also found to be a promising technology for reducing $\mathrm{SO}_{2}$ emissions from ships. Karle and Turner [17] modelled and analyzed the marine chemical aspects of shipboard seawater scrubbing based on a $12 \mathrm{MW}$ engine burning fuel with a $3 \%$ sulphur content. Andreasen and Mayer [18] studied the mechanism of $\mathrm{SO}_{2}$ absorption in seawater with emphasis on scrubbing of marine engine exhaust gas containing $\mathrm{SO}_{2}$. They formulated a model and used it to predict the influence of various parameters on $\mathrm{SO}_{2}$ absorption efficiency such as seawater temperature, partial pressure of $\mathrm{SO}_{2}$, seawater salinity, and seawater alkalinity.

The SW-FGD process imposes relatively low impact on the environment as the main product of this process is sulfate ions $\left(\mathrm{SO}_{4}\right.$ $\left.{ }^{2}\right)$ which is a natural constituent of seawater. The contribution of 10 this product to total sulfur in seawater is negligible. Sulfur in oceans is approximately occupying a $1.5 \mathrm{~m}$ layer, and if all sulfur in coal, oil and acid gas is added to the oceans, the thickness of this layer will increase by the thickness of a sheet of paper $[10,19]$. The increase in the total sulfate content in oceans seawater, if all the sulfur in fossil fuels is deposited in seawater, is approximated to be $905.075 \mathrm{~g}$ compared to a present value of $905.000 \mathrm{~g}$ of sulfate per ton of seawater [13].

\section{Reliability and efficiency of SW-FGD processes}

Several studies in the literature proved the reliability and the high removal efficiency of the SW-FGD systems:

- Utilization of free seawater and air along with their availability results in a significant reduction in the SW-FGD plant operating costs $[20,21]$.

- Waste disposal is not a concern in the SW-FGD process as it does not generate any waste. This eliminates any cost to be spent on waste disposal, and leads to higher reliability [20,22].

- It has been reported that SW-FGD plants with $98.8 \% \mathrm{SO}_{2}$ removal efficiency and $98.8 \%$ availability throughout the year [10]. This indicates that SW-FGD can achieve very high removal efficiencies at higher plant availability and reliability rates.

A simplified process flow diagram for the SW-FGD system is shown in Figure 3. In the SW-FGD process, the absorption process usually takes place in a counter-current packed bed absorber in which the flue gas entering the bottom of the absorber flows upward and come into contact with the falling seawater introduced at the top of the absorber over a randomly packed bed.

The chemistry of the SW-FGD process is described through the instantaneous reactions presented in Figure 4. The $\mathrm{SO}_{2}$ in the upcoming flue gas dissolves in the falling seawater and reacts with it to produce bisulfite $\mathrm{HSO}_{3}$ - (Reaction 1) which is rapidly oxidized to sulfate $\left(\mathrm{SO}_{4}\right)$ (Reaction 2 ) by the oxygen contained either in the flue gas or in the seawater itself. The formed $\mathrm{H}^{+}$in Reactions 1 and 2 acidifies the seawater; therefore, the seawater should be neutralized prior its discharge to the sea. In this case, the seawater neutralizes itself as it utilizes its natural alkalinity capacity (i.e., the bicarbonate, $\mathrm{HCO}_{3}$, and the carbonate, $\mathrm{CO}_{3}^{-2}$, it contains) through Reactions 3 and 4 .

On the other hand, the formed $\mathrm{HSO}_{3}^{-}$in Reaction 1 might be converted to sulfite ions, $\mathrm{SO}_{3}^{-2}$, a chemical oxygen demanding element; thus, it is essential to ensure complete oxidation of all formed $\mathrm{HSO}_{3}^{-}$to $\mathrm{SO}_{4}^{-2}$. In general, the oxygen in the flue gas and seawater is not sufficient to completely oxidize all the formed bisulfite ions $\left(\mathrm{HSO}_{3}^{-2}\right)$. Therefore, forced oxidation using compressed air is employed in most SW-FGD plants $[10,13,23]$.

\section{Design basis of the feeds and products of the SW-FGD scheme}

The basis of selecting the SW-FGD technology its application at ADGAS includes the availability of seawater. The main users of seawater within the ADGAS plant are the surface condensers of the main compressors' steam turbines. The total amount of seawater needed for cooling purposes in Trains 1 and 2 is $85,000 \mathrm{~m}^{3} / \mathrm{h}$. The spent seawater 


\begin{tabular}{|c|c|c|}
\hline Characteristic & Flue Gas to Trains 1 and 2 (each) & Flue Gas to Train 3 \\
\hline $\mathrm{SO}_{2}(\mathrm{~mol} \%)$ & 0.17 & 0.13 \\
\hline $\mathrm{CO}_{2}(\mathrm{~mol} \%)$ & 16.71 & 32.8 \\
\hline $\mathrm{O}_{2}(\mathrm{~mol} \%)$ & 1 & 1 \\
\hline $\mathrm{N}_{2}(\mathrm{~mol} \%)$ & 57.24 & 45.38 \\
\hline $\mathrm{Ar}(\mathrm{mol} \%)$ & 0.59 & 0.5 \\
\hline $\mathrm{H}_{2} \mathrm{O}(\mathrm{mol} \%)$ & 24.28 & 20.19 \\
\hline Pressure $($ barg) & 0.01 & 0.01 \\
\hline Temperature $\left({ }^{\circ} \mathrm{C}\right)$ & 650 & 650 \\
\hline $\mathrm{MW}(\mathrm{kg} / \mathrm{kmol})$ & 28.43 & 31.39 \\
\hline Density $\left(\mathrm{kg} / \mathrm{m}^{3}\right)$ & 0.374 & 0.413 \\
\hline Viscosity $(\mathrm{cP})$ & 0.037 & 0.037 \\
\hline
\end{tabular}

Table 5: Characteristics of Flue Gas Feeds to Trains 1, 2, and 3 of the SW-FGD Plant.

\begin{tabular}{|c|c|}
\hline Composition (mg/L) & Value \\
\hline $\mathrm{Cl}^{-}$ & 25,150 \\
\hline $\mathrm{SO}_{4}^{-2}$ & 3,325 \\
\hline $\mathrm{HCO}_{3}{ }^{-}$ & 92 \\
\hline $\mathrm{CO}_{3}^{-2}$ & 30 \\
\hline $\mathrm{Ca}^{+2}$ & 548 \\
\hline $\mathrm{Mg}^{+2}$ & 1,738 \\
\hline $\mathrm{Na}^{+}$ & 13,374 \\
\hline $\mathrm{SiO}_{2}$ & 5 \\
\hline Temperature $\left.^{\circ}{ }^{\circ} \mathrm{C}\right)$ & 39 \\
\hline $\mathrm{pH}$ & 8.4 \\
\hline Total dissolved solids $(\mathrm{mg} / \mathrm{L})$ & 43,235 \\
\hline Specific Gravity @ $20^{\circ} \mathrm{C}$ & 1.031 \\
\hline Resistivity @ 20 ${ }^{\circ} \mathrm{C}(\mathrm{Ohms})$ & 0.1755 \\
\hline Equivalent salt content $((\mathrm{wt} / \mathrm{wt}) \%)$ & 4.2 \\
\hline Available pressure $(\mathrm{barg})$ & 0.39 \\
\hline Available flow rate $\left(\mathrm{m}^{3} / \mathrm{h}\right)$ & 42,537 \\
\hline
\end{tabular}

Table 6: Characteristics of Seawater to the $\mathrm{SO}_{2}$ Absorbers in the SW-FGD Unit.

\begin{tabular}{|c|c|c|}
\hline Characteristic & Air & BFW \\
\hline $\mathrm{H}_{2} \mathrm{O}(\mathrm{mol} \%)$ & 0 & 100 \\
\hline $\mathrm{O}_{2}(\mathrm{~mol} \%)$ & 21 & 0 \\
\hline $\mathrm{N}_{2}(\mathrm{~mol} \%)$ & 79 & 0 \\
\hline Pressure $($ barg $)$ & 1.01 & 4.51 \\
\hline Temperature $\left({ }^{\circ} \mathrm{C}\right)$ & 30 & 30 \\
\hline $\mathrm{MW}(\mathrm{kg} / \mathrm{kmol})$ & 28.81 & 18.02 \\
\hline Density $\left(\mathrm{kg} / \mathrm{m}^{3}\right)$ & 1.16 & 1004 \\
\hline Viscosity $(\mathrm{cP})$ & 0.019 & 0.797 \\
\hline
\end{tabular}

Table 7: Characteristics of Oxidation Air and Boiler Feed Water (BFW).

from these two trains joins together in a common line which eventually discharges the spent cooling water into the sea.

The feeds to the proposed SW-FGD plant include the flue gas leaving the SRU plant and the seawater coming from the common seawater return header of Trains 1 and 2. The set specifications of the clean gas product from the SW-FGD plant are $8.5 \mathrm{ppm}$ for Trains 1 and 2 and 6.5 ppm Train 3 .

The collected data and design basis of the seawater-flue gas desulfurization scheme include the characteristics of flue gas feeds and sweater feed sweater feed to the $\mathrm{SO}_{2}$ absorbers (Tables 5 and 6), and oxidation air and boiler feed water characteristics (Table 7).

A schematic diagram of the proposed (modified) SW-FGD plant for Trains 1, 2 and 3 is shown in Figure 5. In that diagram the flue gas from the SRUs' incinerators is cooled in a waste heat boiler (WHB) from $650^{\circ} \mathrm{C}$ to $130^{\circ} \mathrm{C}$ then compressed through a gas blower from 1 bar to 2 bars. Further cooling of the flue gas is made before entering the $\mathrm{SO}_{2}$ absorber against the clean flue gas leaving that absorber in a gas-gas heat exchanger. The flue gas in this case is desulfurised using the ADGAS plant spent seawater where its $\mathrm{SO}_{2}$ content is reduced from 0.17 to $0.00085 \mathrm{~mol} \%$ for Trains 1 and 2 and from 0.13 to $0.00065 \mathrm{~mol} \%$ for Train 3 .

The flue gas, sweater, and air flowrates, steam produced and power requirements for Trains 1, 2, and 3 are listed in Table 8 . Note that the seawater is currently pumped to the ADGAS plant at a rate of 42,537 ton/h which is almost double the amount needed for the three $\mathrm{SO}_{2}$ absorbers altogether $(23,256$ ton/h).

Implementation of the SW-FGD scheme depends on the feeds conditions as well as on the required desulfurization efficiency. The feeds include the flue gas from the SRU incinerator and the scrubbing medium (seawater). The flue gas being at low pressure and high temperature is required to be pressurized and cooled before being introduced to the SW-FGD absorber. In addition, the seawater is required to be pressurized to the absorber pressure. The sizing of the SW-FGD absorber includes determination of the diameter and height of the packed bed. Finally, the aeration and neutralization requirement for the seawater effluent from the absorption process has to be established. The completion of these steps will result in a complete SWFGD process package that could be implemented at the ADGAS plant. Hysys simulation has been used to build a complete material balance for the proposed SW-FGD plant but not to size the SW-FGD absorbers.

In order to reduce the load on the flue gas blower, the flue gas from the SRU incinerator has to be pre-cooled in a waste heat boiler where it loses some of its heat to produce low pressure steam. The precooled flue gas is then pressurized to the absorption pressure, which usually results in a temperature increase and hence further cooling is required, e.g. in a waste heat boiler where heat is recovered by hot water to produce steam that can be used in other areas within the plant. The flue gas may be further cooled prior to being introduced to the absorber by the cold clean flue gas leaving that absorber.

The source of seawater supply to the SW-FGD plant is a slip stream

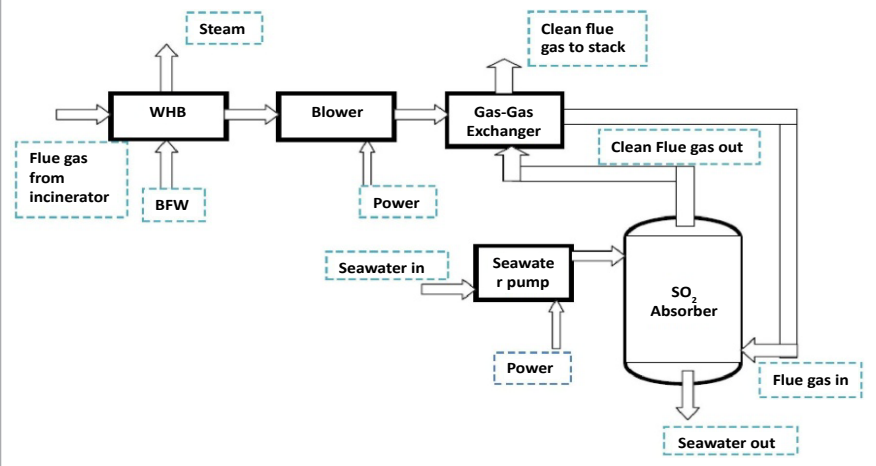

Figure 5: Process Flow Diagram of the SW-FGD Units of Trains 1, 2 or 3

\begin{tabular}{|c|c|c|c|c|c|c|}
\hline Train & $\begin{array}{c}\text { Flue gas } \\
\text { rate } \\
\text { (ton/h) }\end{array}$ & $\begin{array}{c}\text { Seawater } \\
\text { rate } \\
\text { (ton/h) }\end{array}$ & $\begin{array}{c}\text { Oxidation } \\
\text { air } \\
\text { rate } \mathbf{( k g / h )}\end{array}$ & $\begin{array}{c}\text { Steam } \\
\text { produced } \\
\text { (ton/h) }\end{array}$ & $\begin{array}{c}\text { Flue gas } \\
\text { blower } \\
\text { power (kW) }\end{array}$ & $\begin{array}{c}\text { Seawater } \\
\text { pump } \\
\text { power (kW) }\end{array}$ \\
\hline 1 \& 2 & 134.62 & $8,957.90$ & 606.83 & 51.72 & 10,830 & 205 \\
\hline (each) & & & & & & \\
\hline 3 & 97.85 & $5,339.81$ & 364.01 & 36.39 & 7,089 & 188.4 \\
\hline
\end{tabular}

Table 8: Flue Gas, Seawater and Oxidation Air Rates, Steam Produced and Power Requirements for Trains 1, 2, and 3 for the SW-FGD Units. 


\begin{tabular}{|c|c|c|c|}
\hline Parameter & Train 1 & Train 2 & Train 3 \\
\hline Absorber diameter $(\mathrm{m})$ & 5.19 & 5.19 & 4.27 \\
\hline Absorber height $(\mathrm{m})$ & 5.28 & 5.28 & 5.67 \\
\hline
\end{tabular}

Table 9: Sizing of the packed bed $\mathrm{SO}_{2}$ Absorbers.

\begin{tabular}{|c|c|c|}
\hline Parameter & Trains 1 and 2 (each) & Train 3 \\
\hline Total $\mathrm{HSO}_{3}$ - formed $(\mathrm{mol})$ & 8,051 & 4,052 \\
\hline $\mathrm{O}_{2}$ required for aeration $(\mathrm{mol})$ & 4,025 & 2,026 \\
\hline $\mathrm{O}_{2}$ available from flue gas $(\mathrm{mol})$ & 47,359 & 31,174 \\
\hline
\end{tabular}

Table 10: Aeration Requirements for the SW-FGD Plant.

\begin{tabular}{|c|c|c|c|}
\hline Parameter & Train 1 & Train 2 & Train 3 \\
\hline Total $\mathrm{H}^{+}$formed $(\mathrm{mol})$ & $15,941.04$ & $15,941.04$ & $10,546.16$ \\
\hline \multicolumn{3}{|c|}{ Seawater neutralization capacity: } \\
\hline $\mathrm{HCO}_{3}$-available (mol) & $13,929.13$ & $13,929.13$ & $9,168.83$ \\
\hline $\mathrm{CO}_{3}{ }^{2}$-available $(\mathrm{mol})$ & $4,617.81$ & $4,617.81$ & $3,039.67$ \\
\hline Total $(\mathrm{mol})$ & $18,546.94$ & $18,546.94$ & $12,208.50$ \\
\hline
\end{tabular}

Table 11: Neutralization Requirement for the SW-FGD Plant.

from Trains 1 and 2 common seawater return line header. A centrifugal pump is used to bring the pressure of the seawater stream to the absorber.

\section{Relevant calculations for the SW-FGD scheme}

The FGD-Absorber is the main equipment in the SW-FGD scheme where the mass transfer between the flue gas and seawater will take place. The sizing of this absorber requires establishing the seawater flow requirements and finding the absorber height and diameter. Other relevant calculations include aeration requirements for the formed bisulfite ions $\left(\mathrm{HSO}_{3}^{-}\right)$in the absorber and the neutralization requirements for the seawater used in the absorber before being disposed to the sea.

Establishing seawater flow requirement: The minimum amount of seawater required to achieve $99.5 \%$ desulfurization efficiency is established from the solubility data of $\mathrm{SO}_{2}$ in seawater. The general practice is to operate the absorption tower at $25-50 \%$ of the minimum required absorbing solution rate [24]. Rodrı'guez-Sevilla et al. [25] studied the absorption equilibria of dilute $\mathrm{SO}_{2}$ in seawater. The correlation of Al-Enezi et al. [26] has been adopted in this work for the solubility of $\mathrm{SO}_{2}$ in the Arabian Gulf seawater as a function of seawater initial salinity and temperature (Eq. 1). This correlation is valid for a temperature range of 10 to $40^{\circ} \mathrm{C}$, a $\mathrm{SO}_{2}$ partial pressure of $0.0224 \mathrm{kPa}$, $\mathrm{pH}=2.5$ to 2.6 ; and a salinity range of 0 to $40,000 \mathrm{ppm}$.

$$
S=a_{1}+a_{2} T+a_{3} X+a_{4} T^{2}+a_{5} X^{2}
$$

Where $S$ is the solubility of $\mathrm{SO}_{2}$ in seawater $(\mathrm{mol} / \mathrm{L}), T$ is seawater inlet temperature $\left({ }^{\circ} \mathrm{C}\right), X$ is seawater initial salinity $(\mathrm{ppm}), \mathrm{a}_{1}=$ $1.017702 \times 10^{-3}, \mathrm{a}_{2}=-2.71138 \times 10^{-5}, \mathrm{a}_{3}=1.03347 \times 10^{-8}, \mathrm{a}_{4}=2.43198 \times 10^{-7}$, and $\mathrm{a}_{5}=1.24418 \times 10^{-13}$.

The required seawater flow rate to the prospective SW-FGD units is presented in Table 8. This flow rate is based on a calculated $\mathrm{SO}_{2}$ solubility of 0.984 moles of $\mathrm{SO}_{2}$ per $\mathrm{m}^{3}$ of seawater, and a required $99.5 \% \mathrm{SO}_{2}$ removal efficiency.

Diameter of the SW-FGD packed bed absorber: The procedure for sizing packed columns is extensively discussed in literature. The procedure adopted in this work is that of Manyele [24]. A 3-in Super Intalox ceramic packing was chosen here based on the fact that this type and size of packing has a low packing factor and hence is expected to result in an optimum packed bed diameter. On the other hand, the determination of the overall height of a gas transfer unit $\left(H_{\mathrm{OG}}\right)$ and the number of overall mass transfer units $\left(N_{\mathrm{OG}}\right)$ can be achieved either experimentally or calculated from a variety of methods in the literature.

Baaliña [27] developed a laboratory plant where flue gas is scrubbed by seawater pumped directly from the sea. The scrubbing process took place in a counter-current $2 \times 0.25 \mathrm{~m}$ cylindrical stainless steel scrubber packed with $3 / 4$ inch Intalox ceramic saddles to a height of $0.92 \mathrm{~m}$. The experimentally determined $H_{\mathrm{OG}}$ is equal to $0.15 \mathrm{~m}$ at the following conditions $\left(y_{\mathrm{in}}=1.7, L / G=69.7\right.$, desulfurization efficiency $\left.=99.8 \%\right)$. Since the conditions of this work are very close to those of Baaliña et al. (i.e., $y_{\text {in }}=1.7, L / G=66.5$, desulfurization efficiency $=99.5 \%$ ), the Baaliña [27] $H_{\mathrm{OG}}$ value was used here to determine the mass transfer coefficient of the flue gas-seawater system. Details of these calculations and input data are presented elsewhere [28]. Table 9 shows the calculated diameter and height of the packed bed $\mathrm{SO}_{2}$ absorber to achieve the projected $\mathrm{SO}_{2}$ removal efficiency for Trains 1,2 and 3 .

Aeration requirements: The required $\mathrm{O}_{2}$ to achieve complete oxidation of the formed bisulfite ions in the absorption process is calculated for the Reactions 1 and 2 as follows (Figure 4):

According to Reaction 1,

$$
\mathrm{HSO}_{3}^{-} \text {formed }\left[\frac{\mathrm{mol}}{h}\right]=y_{\mathrm{SO}_{2}} \times \text { TotalFlue Gas Flowrate }\left[\frac{\mathrm{mol}}{h}\right]
$$
[mol]

According to Reaction 2, $\mathrm{O}_{2}$ required $[\mathrm{mol}]=0.5 \mathrm{X} \mathrm{HSO}_{3}$-formed

In fact, the amount of $\mathrm{O}_{2}$ in the flue gas is sufficient to completely oxidize all the formed bisulfite ions ( $\mathrm{HSO}_{3}^{-}$). Thus, it is not required to have forced oxidation for the proposed SW-FGD plants. Anyway, the $\mathrm{O}_{2}$ required for aeration in the SW-FGD units of Trains 1, 2 and 3 is presented in Table 10. The air required for oxidation in the SW-FGD units is presented in Table 11.

Neutralization requirements: The formation of $\mathrm{H}^{+}$ions in Reactions 1 and 2 (Figure 4) necessitates the need to neutralize the seawater effluent from the absorber. Usually, the seawater has the capability to neutralize itself depending on its bicarbonate and carbonate ions containment. Karle and Turner [17] made the calculations for the volumes of water required for (i) uptake of Sox (the scrubbing process), (ii) dilution of the scrubbing water to achieve a $\mathrm{pH}$ of 6.5 , (iii) further dilution to achieve a $\mathrm{pH}$ within 0.2 units of thatin the ambient water, and no more than a $1 \%$ reduction in the dissolvedoxygen concentration.

The produced $\mathrm{H}^{+}$ions due to scrubbing reactions (Reactions 1 and 2) are calculated as follows:

$\mathrm{H}^{+}$produced in Reaction $1\left[\frac{\mathrm{mol}}{\mathrm{h}}\right]=$ Total $\mathrm{SO}_{2}$ Absorbed $=y_{\mathrm{SO}_{2}} \mathrm{x}$ Total Flue Gas Flow $\left[\frac{m o l}{h}\right]$

$\mathrm{H}^{+}$produced in Reaction $2\left[\frac{\mathrm{mol}}{\mathrm{h}}\right]=\mathrm{HSO}_{3}^{-}$formed $\left[\frac{\mathrm{mol}}{h}\right]=y_{\mathrm{SO}_{2}} \mathrm{x}$ Total Flue Gas Flow $\left[\frac{m o l}{h}\right]$

Total $\mathrm{H}^{+}$produced $=\mathrm{H}^{+}$produced in Reaction $1+\mathrm{H}^{+}$produced in Reaction 2 (4)

Where $y_{\mathrm{SO}_{2}}$ is the mole fraction of $\mathrm{SO}_{2}$ in the flue gas.

The seawater neutralization capacities in terms of bicarbonate $\left(\mathrm{HCO}_{3}{ }^{-}\right)$and carbonate $\left(\mathrm{CO}_{3}^{-2}\right)$ ions (Reactions 3 and 4$)$ are calculated as follows:

$$
\mathrm{HCO}_{3}^{-}\left[\frac{g-m o l}{h}\right]=x_{\mathrm{HCO}_{3}^{-}}\left(\frac{m g}{1}\right)\left(\frac{1 g}{1000 \mathrm{mg}}\right)\left(\frac{1}{\mathrm{MW}_{\mathrm{HCO}}}\right)\left(\frac{1000 \mathrm{l}}{1 \mathrm{~m}^{3}}\right) \times \text { Seawater flow }\left(\frac{m^{3}}{h}\right)
$$




\begin{tabular}{|c|c|c|c|c|}
\hline Equipment & Quantity & Purchased Cost (\$) & Bare Module Cost (\$) & Total Module Cost (\$) \\
\hline Train 1 and 2 Flue Gas Blowers & 2 & $2,700,000$ & $7,380,000$ & $11,180,000$ \\
\hline Train 3 Flue Gas Blower & 1 & $1,020,000$ & $2,790,000$ & $4,230,000$ \\
\hline Train 1 and 2 Flue Gas Blower Drivers & 2 & 850,000 & $2,980,000$ & $4,500,000$ \\
\hline Train 3 Flue Gas Blower Driver & 1 & 398,000 & $1,390,000$ & $2,110,000$ \\
\hline Train 1, 2 and 3 Waste Heat Boilers & 3 & 81,300 & 274,200 & 323,400 \\
\hline Train 1, 2 and 3 Gas-Gas Heaters & 3 & 81,300 & 267,900 & 316,200 \\
\hline Train 1 and 2 Seawater Pumps & 2 & 111,000 & 442,000 & 522,000 \\
\hline Train 3 Seawater Pump & 1 & 51,900 & 207,000 & 244,000 \\
\hline Train 1 and 2 FGD Absorbers & 2 & 486,000 & $3,300,000$ & $3,900,000$ \\
\hline Train 3 FGD Absorber & 1 & 170,000 & $1,071,000$ & $1,264,000$ \\
\hline Train 1 and 2 UGA Feed Heaters & 2 & 54,400 & 180,400 & 274,000 \\
\hline Total & & $6,003,900$ & $20,282,500$ & $28,863,600$ \\
\hline
\end{tabular}

Table 12: Estimated capital cost for the equipment needed for the proposed SW-FGD schemeusing CAPCOST [29]. CEPCI = 509.1 [31].

\begin{tabular}{|c|c|c|}
\hline Equipment & Quantity & Utility used \\
\hline Train 1 and 2 Flue Gas Blower Drivers & 2 & Medium pressure steam \\
\hline Train 3 Flue Gas Blower Driver & 1 & Medium pressure steam \\
\hline Train 1 and 2 Seawater Pumps & 2 & Electricity \\
\hline Train 3 Seawater Pump & 1 & Electricity \\
\hline Train 1 and 2 UGA Feed Heaters & 2 & Low pressure steam \\
\hline
\end{tabular}

Table 13: Annual utilities cost for the proposed SW-FGD Plant using CAPCOST.

$$
\mathrm{CO}_{3}^{-2}\left[\frac{g-m o l}{h}\right]=x_{\mathrm{CO}_{3}^{-2}}\left(\frac{m g}{1}\right)\left(\frac{1 g}{1000 m g}\right)\left(\frac{1}{M W_{C O_{3}^{-2}}}\right)\left(\frac{1000 l}{1 m^{3}}\right) \times \text { Seawater flow }\left(\frac{m^{3}}{h}\right)
$$

Where $x$ is ion concentration in seawater $(\mathrm{mg} / \mathrm{l})$ and $\mathrm{MW}$ is ion molecular weight (g/g-mol).

Further neutralization of the spent seawater from the SW-FGD plant is achieved through returning the spent seawater to common seawater return header of Trains 1 and 2. Upon such, the spent seawater will be mixed with fresh seawater before being discharged into the sea. The mixing of the spent cooling water with fresh seawater prior discharge will enhance the properties of the spent seawater. The neutralization requirements for Trains 1, 2 and 3 FGDs are presented in Table 11

\section{Cost estimation of $\mathrm{SO}_{2}$ minimization schemes}

The drive of this work is purely environmental; reduce the global, regional and local impacts of $\mathrm{SO}_{2}$ emissions from the ADGAS plant, and ensure compliance of all $\mathrm{SO}_{2}$ emission sources within the ADGAS plant to the standards of the United Arab Emirates Federal EnvironmentalAgency (UAE-FEA). The cost associated with the selected $\mathrm{SO}_{2}$ minimization schemes includes the capital cost for the proposed SW-FGD units (Table 12), its associated annual utility and operating cost (Table 13). The cost of operating labor is $\$ 750,000$ per year as estimated by CAPCOST [29]. The SW-FGD units will produce 140 ton $/ \mathrm{h}$ medium pressure steam $\left(\mathrm{T}=220^{\circ} \mathrm{C} ; \mathrm{P}=9.41 \mathrm{barg}\right)$. The price of medium pressure steam is $\$ 3.34 /$ ton; this price is based on actual steam turbine for fixed process steam loads [30]. The price of the produced steam will be $\$ 2,973,531$. The production of medium pressure steam will result in reducing the demand of medium and low pressure steams within ADGAS. The direct result is eliminating the need to produce 140 ton/h of high pressure steam in ADGAS boilers. For a high pressure steam price of $\$ 5.78 /$ ton [31], the saving of the produced medium pressure steam from the proposed flue gas desulfurization plants is $\$ 5,145,811$ per year. The total income and savings will be $\$ 8,119,343$ per year. As a result, this will cover the associated annual utilities and operating cost of $\$ 5,389,320$ per year. The net yearly income is $\$ 2,730,022$. The payback period of this will be 10.57 years.
In addition, the $\mathrm{SO}_{2}$ minimization schemes will result in a positive impact and savings that will be gained from the achievement of an improved air quality, and consequently a better environment, which will lead to a better occupational health impact and less risk to the health of the workers. The later will lead to an increase in the productivity of the workers and enhancing the performance of the company they work in.

\section{Conclusions and Recommendations}

This work focuses on quantifying $\mathrm{SO}_{2}$ emissions from ADGAS following an approach centered on equipping the SRUs with FGD units, and maximizing $\mathrm{H}_{2} \mathrm{~S}$ diversion from fuel gas to SRUs. Upon such an approach, most of the $\mathrm{H}_{2} \mathrm{~S}$ in the fuel gas will be directed to the SRUs, and will be converted to sulfur product. Unconverted $\mathrm{H}_{2} \mathrm{~S}$ will be routed to the SRUs incinerator where it is oxidized to $\mathrm{SO}_{2}$ and then directed to the FGD units where it is scrubbed by the desulfurization solution and converted into the harmless products that are disposed safely and economically. As a result, the $\mathrm{SO}_{2}$ emissions will be largely reduced. This approach guarantees optimum $\mathrm{SO}_{2}$ minimization; thus, minimizing the

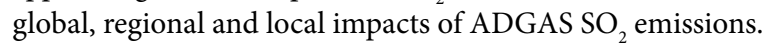

Two minimization schemes have been proposed in this work; fuel gas sweetening scheme and flue gas desulfurization scheme. (1) In the fuel gas sweetening schemes, Trains 1 and $2 \mathrm{UGA} \mathrm{H}_{2} \mathrm{~S}$ removal efficiency will be maximized through replacement of the packing with a higher efficiency packing and the catering of the required fuel gas by ADMA-GTs which at the current conditions utilize untreated gas. (2) In Flue Gas Desulfurization (FGD) scheme, the $\mathrm{SO}_{2}$ in the flue gas will be scrubbed by the readily available seawater as an absorbing medium. The seawater will absorb $\mathrm{SO}_{2}$ and convert it to harmless $\mathrm{SO}_{4}$ ions; a natural constituent of seawater. The seawater will be eventually disposed into the open sea.

- Implementation of the proposed fuel gas sweetening and flue gas desulfurization schemes exposes the minimum foot-print within ADGAS plant in Das Island compared to any other technologies. Also, the proposed schemes do not depend on continuous resource supply from outside the Das Island. 
Citation: Abu-Eishah SI, Babahar HSA, Maraqa M (2014) Minimization of $\mathrm{SO}_{2}$ Emissions at ADGAS (Das Island, UAE): I- Current vs. Modified Schemes. J Pet Environ Biotechnol 5: 173. doi:10.4172/2157-7463.1000173

Page 10 of 10

- Implementation of the proposed $\mathrm{SO}_{2}$ minimization schemes is expected to reduce the total $\mathrm{SO}_{2}$ emissions by $77 \%$ (from 27,532 to 6364 ton/yr): The fuel gas sweetening scheme is expected to reduce $\mathrm{H}_{2} \mathrm{~S}$ content in the fuel gas by $94 \%$ (from 1200 to 72 ppm) and result in decreasing the total $\mathrm{SO}_{2}$ emissions due to fuel gas usage by $98 \%$ (from 10,092 to $168 \mathrm{ton} / \mathrm{yr}$ ). The flue gas desulfurization scheme is expected to reduce the $\mathrm{SO}_{2}$ emissions due to incomplete sulfur recovery in the SRUs by $99.5 \%$ (from 11,299 to 57 ton/yr)

- The total module cost of implementing the suggested $\mathrm{SO}_{2}$ minimization schemes is $\$ 28,863,600$. The annual cost of the associated utilities and operating cost is $\$ 4,639,300$. The income and savings that will be gained from the produced steam is $\$ 8,119,300$ per year. Thus, implementing the $\mathrm{SO}_{2}$ minimization schemes will cover all operating and utilities cost and will yield a net annual income of $\$ 2,730,000$. The payback period on the original investment is 10.6 years.

The implementation of the proposed $\mathrm{SO}_{2}$ minimization schemes is expected to have all $\mathrm{SO}_{2}$ emission sources (except the sour flares due to flash gas flaring) comply with UAE-FEA limits $\left(500 \mathrm{mg} / \mathrm{Nm}^{3}\right)$. Implementation of the flash gas recovery system will result in the compliance of all trains sour flare with the UAE-FEA limits. Also the $\mathrm{SO}_{2}$ emissions will have the potential to challenge any future stringent UAE-FEA limits with high level of confidence as the emission rates at the proposed conditions are reduced to about $5 \%$ of the standard (i.e., $25 \mathrm{mg} / \mathrm{Nm}^{3}$ ). This will be presented in Part II of this work.

\section{References}

1. Peavy HS, Rowe DR, Tchobanoglous G (1985) Environmental Engineering Europe: McGraw Hill Education.

2. World Health Organization Europe (2005) Air quality guidelines. Global update 2005. Particulate matter, ozone, nitrogen dioxide and sulfur dioxide.

3. US EPA (2009) Sulfur Dioxide: Health and Environmental Impacts of $\mathrm{SO}_{2}$.

4. Environmental Agency-Abu Dhabi (2006) State of the Environment Abu Dhabi: Key Findings.

5. Atkins WS (1997) Aerial Discharge Baseline Survey - Das Island.

6. Al Nuaimi A (1999) Management of Emissions at ADGAS. UAE University, Al Ain, UAE.

7. Koch-Glitsch (2003) IMTP ${ }^{\circledR}$ High Performance Packing, Bulletin KGIMTP-2 2M1303E.

8. Norton HY-PAK (1975) Norton Chemical Process Products, HY-PAK High Performance Metal Tower Packing, Bulletin HY-40, ADGAS Process Engineering Library Records.

9. Shell Global Solutions (2005) ADGAS Flares and Emissions Study: Consolidated Report.

10. Kohl AL, Nielsen R (1997) Gas Purification. Gulf Professional Publishing UAE.

11. Mokhatab S, Poe W, Speight JG (2006) Handbook of Natural Gas Transmission and Processing Chemical, Petrochemical \& Process. Gulf Professional Publishing UAE.

12. Oikawa K, Yongsiri C, Takeda K, Harimoto T (2003) Seawater flue gas desulfurization: Its technical implications and performance results. Environ Prog 22: 67-73.
13. Kyte WS (1995) Desulphurisation 4 : a symposium organised by the Institution of Chemical Engineers ... held at the University of Sheffield, 20-21 June 1995 Rugby, Warwickshire : Institution of Chemical Engineers, cop.

14. Srivastava RK (2000) Controlling SO Emissions: A Review of Technologies US Environmental Protection Agency Washington DC USA.

15. Tandon PN, Ramalingam P (1998) Alternative models for the disposal of flue gases in deep sea. Environmental problems in coastal regions 1: 185-196.

16. Importance of Information Management for Environmentally Sound Technologies (ESTs) Transfer (UNEP/GEC Session) (2005) Reuse of Seawater for Flue Gas Desulfurization. FGD Project Headquarters Japan.

17. Karle IM, Turner DR (2007) Seawater scrubbing - reduction of SOx emissions from ship exhausts. AGS Office at Chalmers Göteborg Sweden.

18. Andreasen A, Mayer S (2007) Use of Seawater Scrubbing for SO2 Removal from Marine Engine Exhaust Gas. Energy Fuels 21: 3274-3279.

19. Nyman GBG, Tokerud A (1991) Seawater Scrubbing Removes SO2 from Refinery Flue Gases. Oil and Gas J 89: 51-55

20. Khawaji AD, Wie JM (2005) Seawater Scrubbing for the Removal of Sulfur Dioxide in a Steam Turbine Power Plant. ASME 2005 Power Conference Chicago, Illinois, USA April 5-7.

21. Bockman O, Tokerud A, Gramme P, Terjesen S, Thurmann-Nielsen E (1974) Process for Removal of Sulphur dioxide from Flue-Gases by Absorption in SeaWater. AFIPS Conference Proceedings.

22. Tokumura M, Baba M, Znad HT, Kawase $Y$ (2006) Neutralization of the Acidified Seawater Effluent from the Flue Gas Desulfurization Process: Experimental Investigation, Dynamic Modeling, and Simulation. Ind Eng Chem Res 45: 63396348

23. Power Engineering International (2004) Emission Control: Seawater FGD debuts at Alba.

24. Manyele SV (2008) Toxic Acid Gas Absorber Design Considerations for Air Pollution Control in Process Industries. Educational Research and Reviews 3 : 137-147.

25. Rodríguez-Sevilla J, Álvarez M, Díaz MC, Marrero MC (2004) Absorption Equilibria of Dilute SO2 in Seawater. J Chem Eng Data 49: 1710-1716.

26. Al-Enezi G, Hisham, El-Dessouky H, Fawzi N (2004) Solubility of Sulfur Dioxide in Seawater. Ind Eng Chem Res 40: 1434-1441.

27. Baalina A (2008) A Practical Case Study of Scrubbing Systems for Inert Gas Supply. European Journal of Scientific Research 21: 64-70.

28. Babahar HSA (2009) Investigation on the Minimization of Sulfur Dioxide Emissions at Abu Dhabi Gas Liquefaction Company Limited (ADGAS) and Its Impact on Ambient Air Quality. UAE University, Al Ain, UAE.

29. Turton R, Bailie RC, Whiting WB, Shaeiwitz JA (2002) Analysis, Synthesis and Design of Chemical Processes. Prentice Hall USA.

30. Varbanov P, Smith R (2005) What's the Price of Steam? Chemical Engineering Progress Magazine.

31. Chemical Engineering (2009) Economic Indicators: CEPCI. 